\title{
The geology of the Nawish quadrangle of Ceres: The rim of an ancient basin
}

\author{
Alessandro Frigeri $^{\mathrm{a}, *}$, Nico Schmedemann ${ }^{\mathrm{b}}$, David Williams ${ }^{\mathrm{c}}$, Yann Chemin ${ }^{\mathrm{d}}$, Melissa Mirino ${ }^{\mathrm{e}}$, \\ Andrea Nass $^{\mathrm{f}}$, Filippo Giacomo Carrozzo ${ }^{\mathrm{a}}$, Julie Castillo-Rogez ${ }^{\mathrm{g}}$, Debra L. Buczkowski ${ }^{\mathrm{h}}$, \\ Jennifer E.C. Scully ${ }^{g}$, Ryan Park ${ }^{g}$, David A. Crown ${ }^{\mathrm{i}}$, Scott C. Mest ${ }^{\mathrm{i}}$, Costanzo Federico ${ }^{\mathrm{a}}$, \\ Eleonora Ammannito ${ }^{j}$, Maria Cristina De Sanctis ${ }^{\mathrm{a}}$, Carol A. Raymond ${ }^{\mathrm{g}}$, Christopher T. Russell ${ }^{\mathrm{k}}$ \\ a Istituto Nazionale di Astrofisica (INAF), Istituto di Astrofisica e Planetologia Spaziali (IAPS), Rome, Italy \\ ${ }^{\mathrm{b}}$ Max-Planck-Institute for Solar System Research, Göttingen, Germany \\ ${ }^{\mathrm{c}}$ School of Earth and Space Exploration, Arizona State University, Tempe, AZ, USA \\ d Joint Research Center, Ispra, Italy \\ e Open University, Walton Hall, Milton Keynes, United Kingdom \\ ${ }^{\mathrm{f}}$ German Aerospace Center, Institute of Planetary Research, Berlin, Germany \\ ${ }^{g}$ Jet Propulsion Laboratory, California Institute of Technology, Pasadena, CA, USA \\ ${ }^{\text {h }}$ Space Department, Johns Hopkins University Applied Physics Laboratory, Laurel, MD, USA

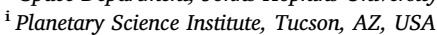 \\ ${ }^{\mathbf{j}}$ Italian Space Agency, Rome, Italy \\ ${ }^{\mathrm{k}}$ Institute of Geophysics and Planetary Physics, University of California, Los Angeles, CA, USA
}

\section{A R T I C L E I N F O}

\section{Keywords:}

NASA/Dawn

Ceres

Geology

Geologic mapping

GIS

\begin{abstract}
A B S T R A C T
Herein we present the geology of the Nawish quadrangle, located in the equatorial region of dwarf planet Ceres, named after one of the most prominent craters of the area. Geologic mapping was based on the image mosaics and digital terrain models derived from Dawn Framing Camera data. Interpretation of geologic units was supported by supplemental data, such as the multi spectral color images from the Framing Camera, and the spectral parameters derived from the Visible and Infrared Spectrometer (VIR) data, as well as Dawn gravity data. There is not a primary feature that dominates the geology of Nawish quadrangle, but rather several terrains overlap, and their relations explain the geology of the area. Crater size frequency distributions show that Nawish quadrangle is dominated by two distinct time domains. The central and eastern part of the quadrangle is topographically elevated, which we define as cratered highlands, and contains the older domain. The western lowlands show two younger domains related to impact craters Kerwan and Dantu, including the Kerwan smooth material and Dantu ejecta. This variation of elevation within the Nawish quadrangle is more than the half of the global topographic altitude variation on Ceres. Analysis and comparison of the topography of the Nawish quadrangle with surrounding ones shows that this quadrangle is dominated by the topography of the rim sector of a large, $>800 \mathrm{~km}$ ancient impact basin, most likely the putative Vendimia Planitia. The Nawish quadrangle thus represents a sector of Ceres which has not undergone large-scale, post-Kerwan, intermediate age-events, but rather represents a place on Ceres where a well-preserved relict of old cerean crust can be studied, together with ejecta from more recent impact events.
\end{abstract}

\section{Introduction}

In a similar way in which the Dawn (Russell and Raymond, 2011) Science Team mapped the asteroid (4) Vesta (Yingst et al., 2014; Williams et al., 2014), herein we geologically map dwarf planet Ceres following a 15-quadrangle scheme suggested for mapping small bodies
(Greeley and Batson, 2007; Roatsch et al., 2016; Williams et al., 2018b, Introductory paper). Quadrangle mapping build on the lower resolution global geologic mapping to investigate in detail the geologic feature and relations in a specific area of Ceres. In this paper we discuss results from the geological mapping of the Ac-8 Nawish quadrangle, which is one of the five quadrangles that cover the equatorial belt of Ceres

\footnotetext{
* Corresponding author.

E-mail address: alessandro.frigeri@inaf.it (A. Frigeri).
} 


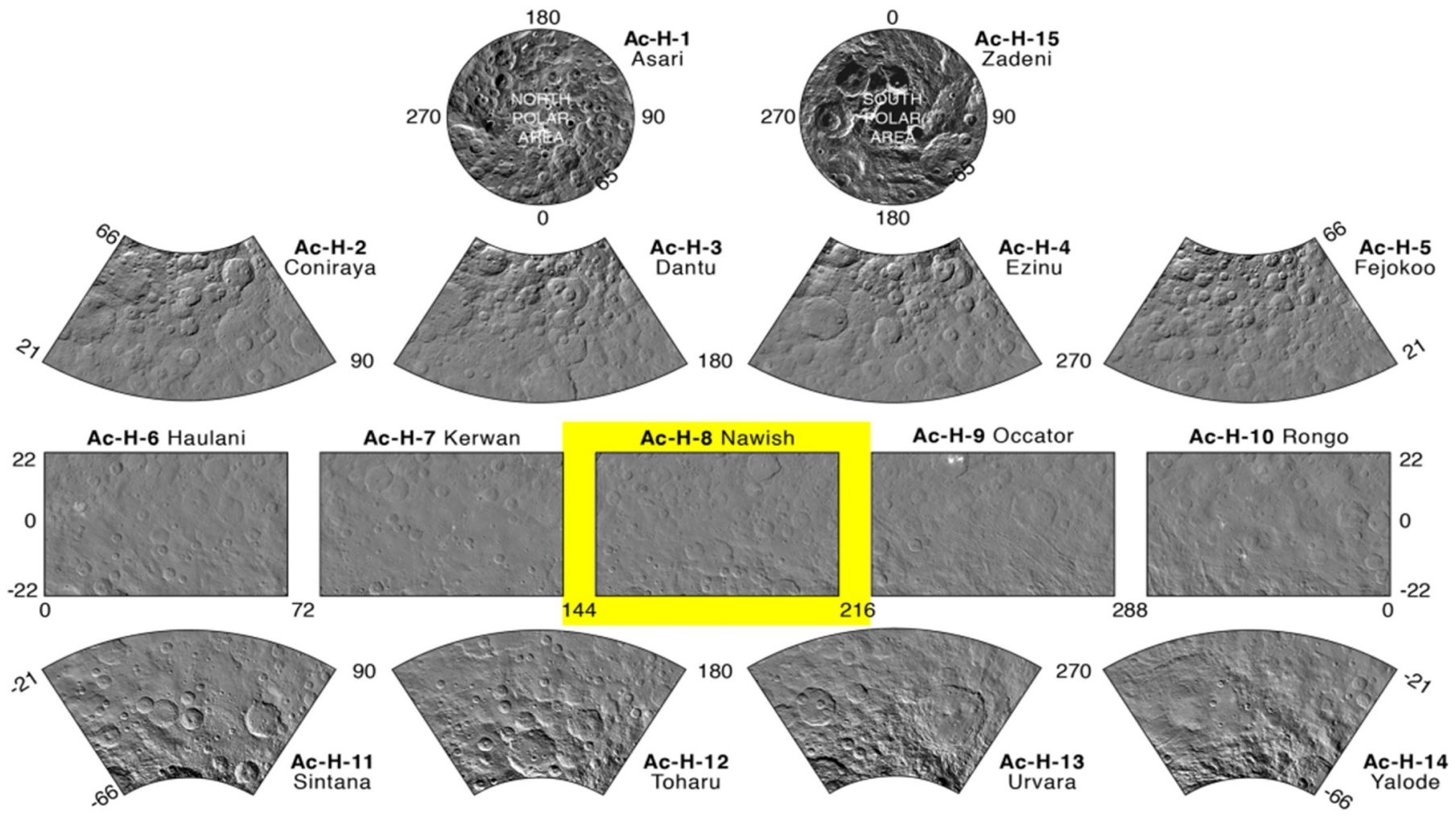

Fig. 1. The yellow frame indicates the Ac-8 Nawish quadrangle within the context of the 15-tiles for Ceres, following the scheme suggested for mapping small bodies (Greeley and Batson, 1990; Roatsch et al., 2016). (For interpretation of the references to colour in this figure legend, the reader is referred to the web version of this article.)

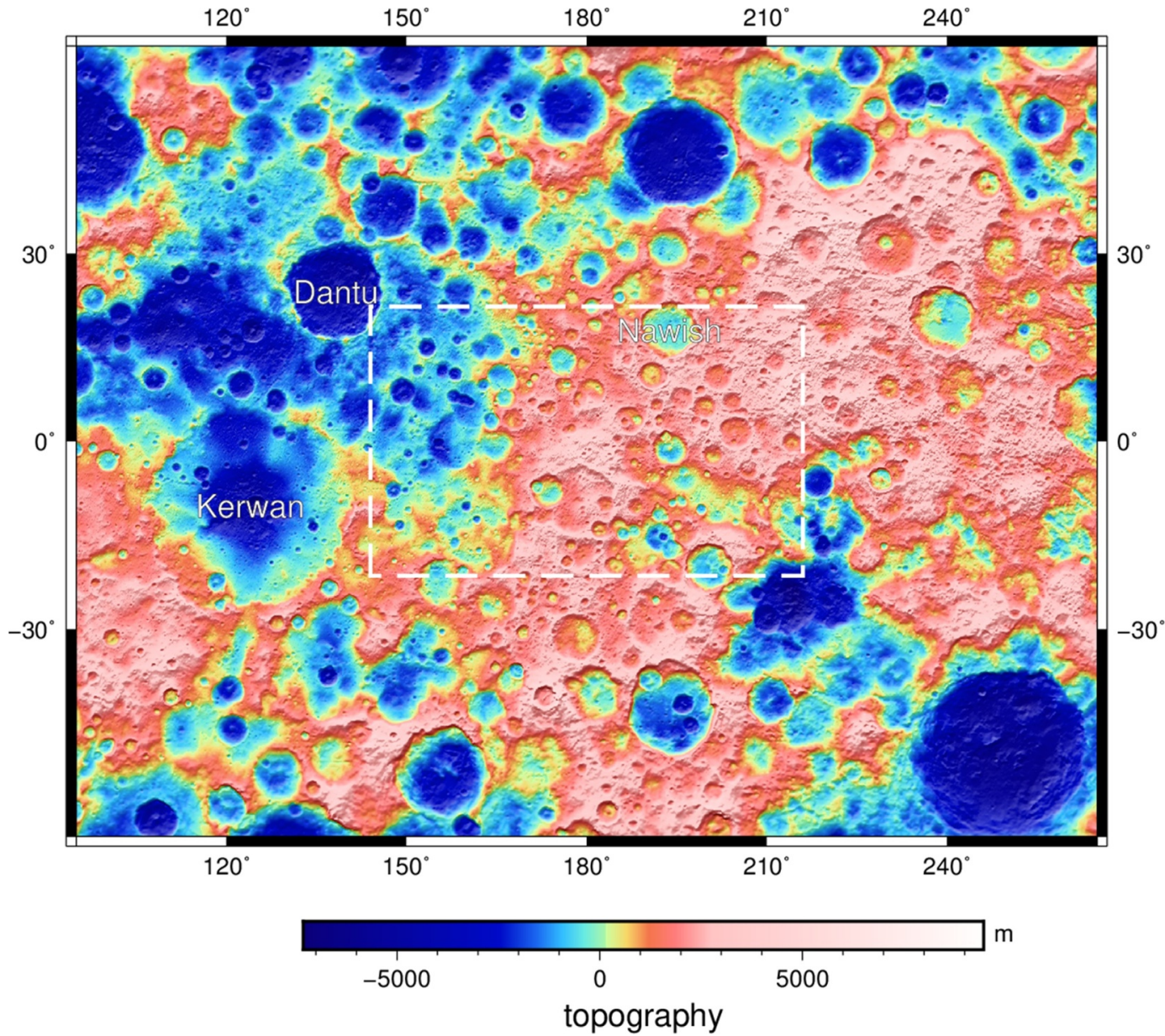

Fig. 2. Digital Terrain Model of Ac-8 Nawish quadrangle and its surroundings. The white dashed line indicates the quadrangle boundaries of Nawish. Westward of Nawish, Kerwan and Dantu craters dominate the morphology. 

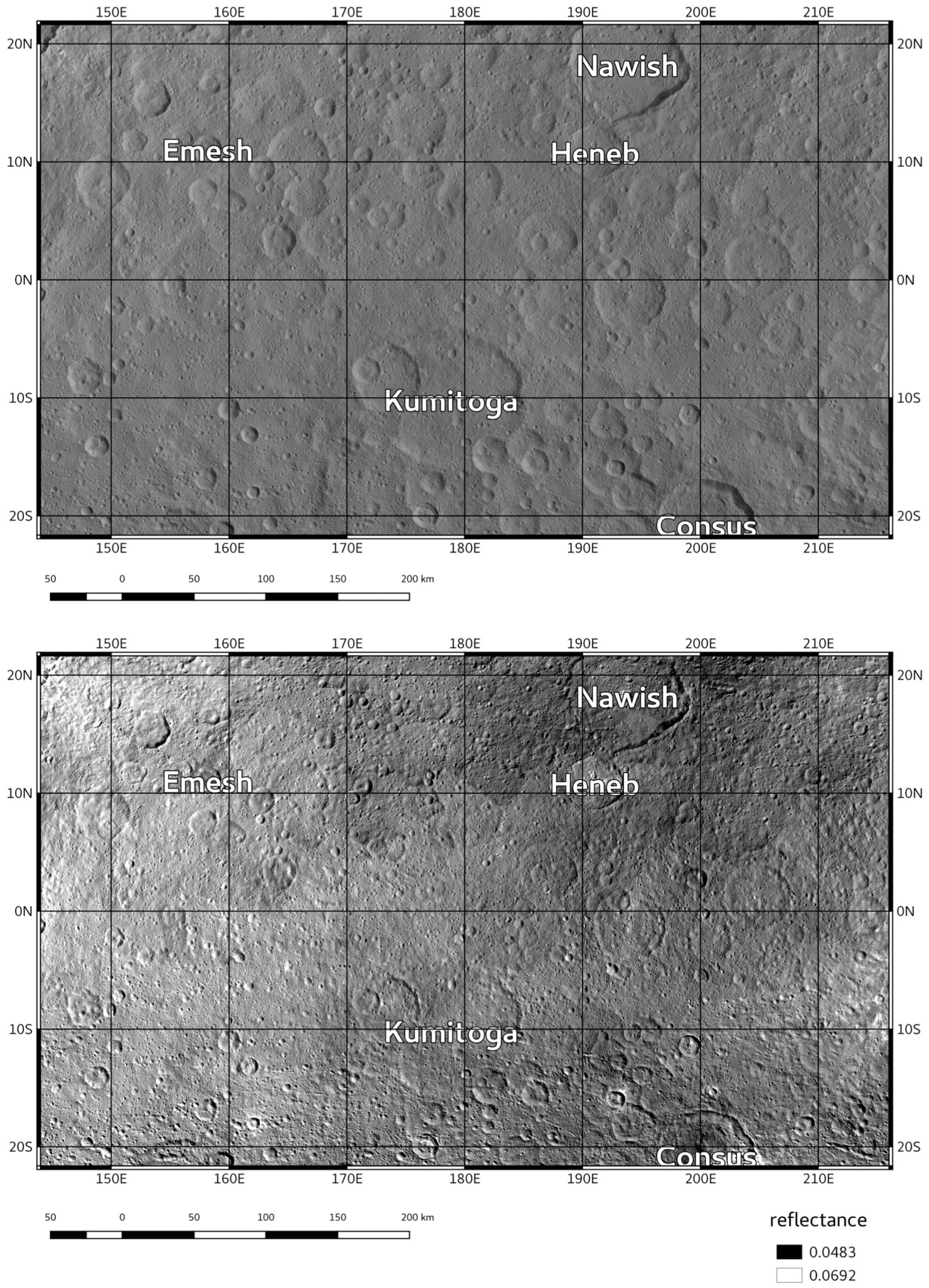

Fig. 3. Image mosaics of Nawish from Framing Camera data with the official IAU nomenclature for Ceres. Projection is equidistant cylindrical, and coordinates are relative to the Kait system (Roatsch et al., 2016), scale is true at the equator. Top: LAMO data ( $35 \mathrm{~m} / \mathrm{pixel}$ ), which has been used as the mapping base together with the topographic data. Bottom: photometrically corrected HAMO data $(140 \mathrm{~m} /$ pixel), which has been used to detect albedo variations and to map bright spots. Data for both maps has been processed and provided by the German Aerospace Center (DLR). 
(Fig. 1). Whereas the global geomorphological and geological global studies (Buczkowski et al., 2016; Mest et al., 2017a; Mest et al., 2017b) were produced on the basis of data from high mapping orbits at Ceres (Survey and High Altitude Mapping Orbit - HAMO, respectively) at the 1:10 M scale, for this geologic map we are using the highest resolution data available from the NASA Dawn campaign at Ceres, i.e., from the Low Altitude Mapping Orbit (LAMO) campaign (image spatial resolution of $35 \mathrm{~m} / \mathrm{pixel}$ ). The scale for the quadrangle mapping of Ceres is set at $1: 500,000$.

Our mapping has utilized two types of data: 1) base maps of Framing Camera (FC, Sierks et al. (2011)) LAMO images and stereobased digital terrain models (Preusker et al., 2016), and 2) supplementary data deriving from other experiments on-board Dawn. These other experiments from Dawn provide compositional and gravimetric information which assisted the interpretation. Elemental abundance information is reported from the Gamma Ray and Neutron Detector (GRaND, Prettyman et al. (2011)), whereas mineralogy is obtained from the Visible and Infrared spectrometer (VIR, De Sanctis et al. (2011)). The interpretation of data from the radio science experiment allows to extract information on the gravity field (Park et al., 2016). The base maps and the supplementary data were used to produce the 1:500,000 scale geologic map and to describe the geologic evolution of the area of Nawish quadrangle on Ceres.

\section{Regional setting and topography}

The area covered by Nawish quadrangle spans from longitude $144^{\circ} \mathrm{E}$ to longitude $216^{\circ} \mathrm{E}$ and from latitude $22^{\circ} \mathrm{S}$ to latitude $22^{\circ} \mathrm{N}$ (Fig. 1). The dimensions are 590 by $360 \mathrm{~km}$ for an area of 234,800 square kilometers. The quadrangle's name comes from the $80 \mathrm{~km}$ wide crater Nawish, which is in the northern sector of the quadrangle, centered at $193.73^{\circ} \mathrm{E}-18.32^{\circ} \mathrm{N}$.

Fig. 2 shows the topography of the area computed as the height over an ellipsoid with a semi-major axis of $482 \mathrm{~km}$ and a semi-minor axis of $446 \mathrm{~km}$. The elevation within Nawish quadrangle ranges from $-3800 \mathrm{~m}$ to $5900 \mathrm{~m}$.

We divide the topography of Nawish quadrangle into two distinct zones: the cratered highlands of the central and eastern sector, and the eastern lowlands. The largest craters of the area are Nawish, Heneb and Kumitoga, located in the highlands (Fig. 3, top) and an unnamed very degraded crater centered at $158 \mathrm{~W}-0 \mathrm{~N}$ in the lowlands. The lowlands we recognize are part of the putative Vendimia Planitia basin, first proposed in Marchi et al. (2016) and further discussed in Hiesinger et al. (2016). The Bouguer anomaly in the Dawn gravity data fits well with the topographic surface trend and there are no local gravity anomalies in the study area (Park et al., 2016, Ermakov et al., 2017).

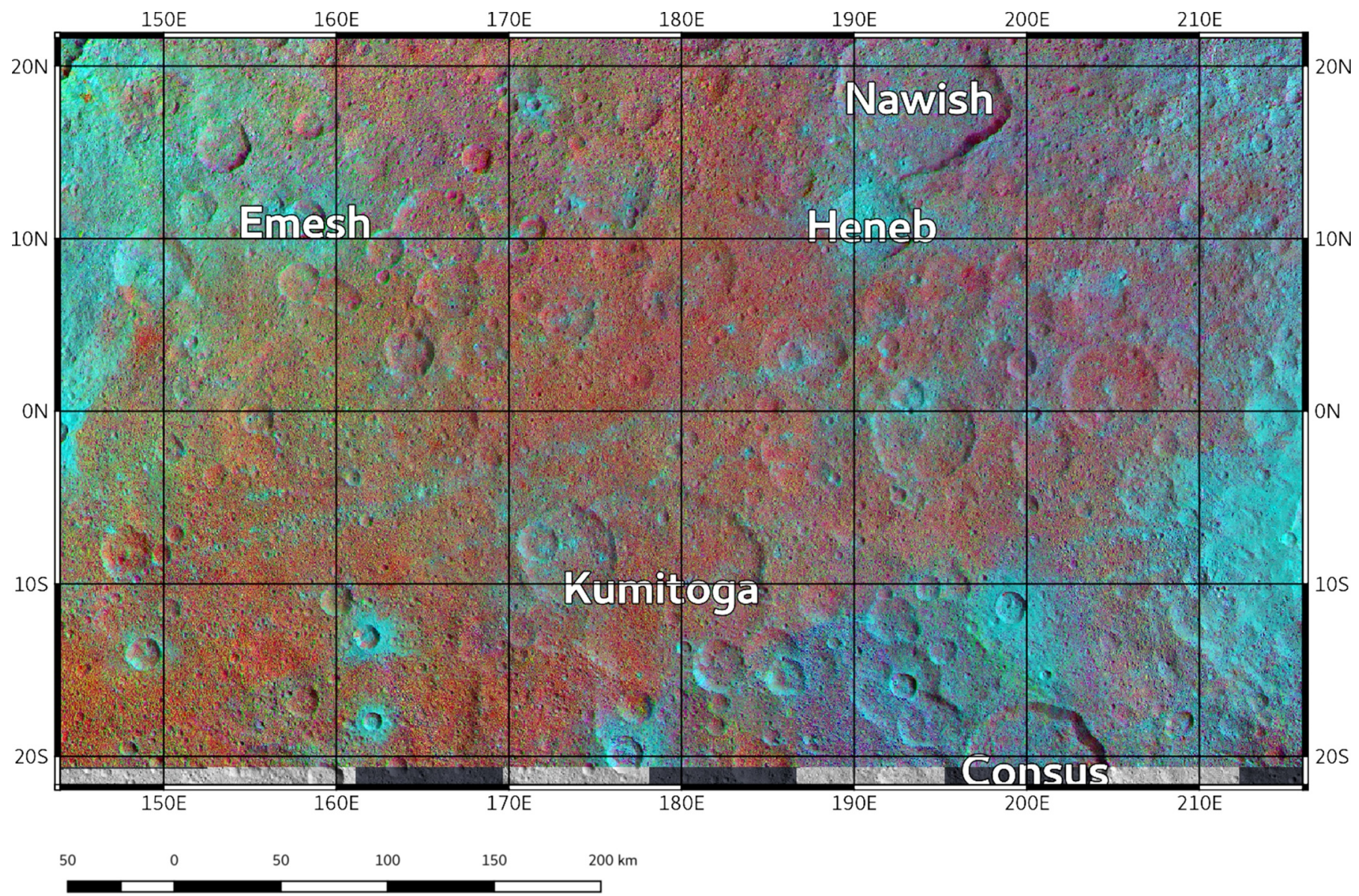

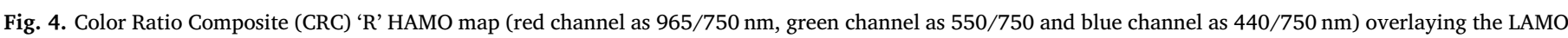

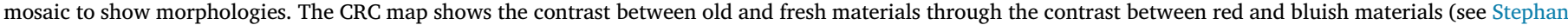
et al., 2017, Jaumann et al., 2016). (For interpretation of the references to colour in this figure legend, the reader is referred to the web version of this article.) 

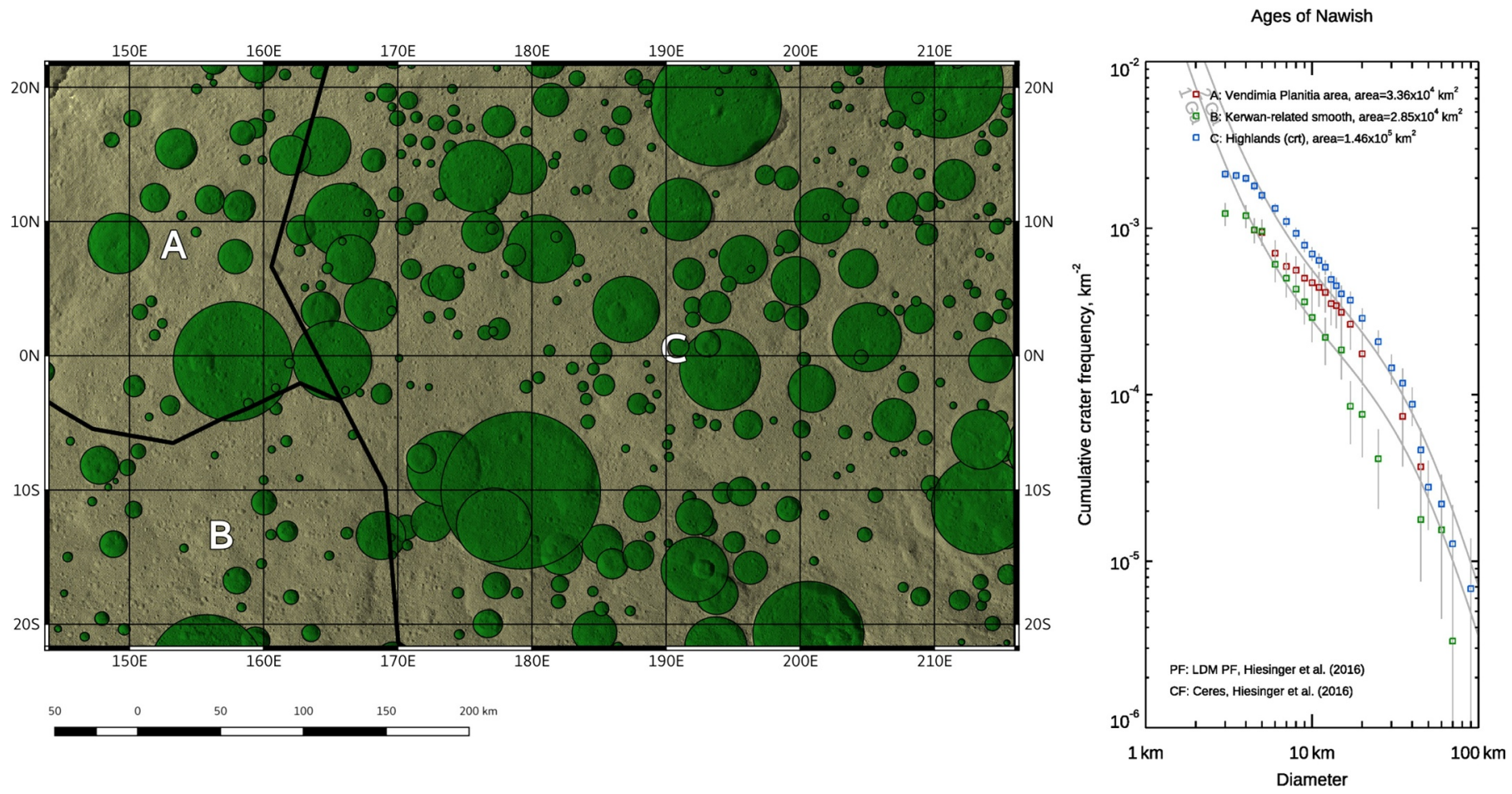

Fig. 5. Crater Size Frequency Distribution (CSFD) for Nawish quadrangle. Left: map of craters considered in our analysis. Right: cumulative plot of mapped craters. Absolute ages are computed with the production function (PF) and crater function (CF) for Ceres, the two isochrons correspond to 1 and $2 \mathrm{Ga}$. We divided Nawish in three areas. Area A (red squares in the CSFD graph) shows resurfacing effects of younger materials infilling over the older ones. Area B (green squares) is representative of the smooth unit with a model age of $1.1 \mathrm{Ga}$, while area C (blue squares) is the old cratered terrain (crt) unit, with an age of $2.5 \mathrm{Ga}$. See the supplementary material for the detailed cumulative graphs of the single areas with randomness analysis (Michael et al., 2012) and model age estimation by Poisson method (Michael et al., 2016). (For interpretation of the references to colour in this figure legend, the reader is referred to the web version of this article.)

\section{Data and methods}

The base map for the geologic mapping comes from the Dawn Framing Camera in the form of image mosaics and stereo photogrammetry-derived digital terrain models. The FC image frames have been mosaicked and referenced to the International Astronomical Union (IAU) approved coordinate system, tied to the $400 \mathrm{~m}$ diameter crater Kait, at $0^{\circ} \mathrm{E}$ and $2^{\circ} \mathrm{S}$ (Roatsch et al., 2017). Global image mosaics at different resolutions have been produced for each of the scientific orbit phases. The image mosaic used for the basemap of this work has been produced using FC data acquired during the Low Altitude Mapping Orbit (LAMO), at a spatial resolution of $35 \mathrm{~m}$ per pixel (Fig. 3, top) (Roatsch et al., 2017). The overlapping FC frames have been processed in order to extract a digital terrain model, which has been used to produce the topography of the area (Preusker et al., 2016).

In addition to the base maps, we also used other data to support the analysis of the surface of Nawish quadrangle. Data from the seven channels of the Framing Camera from High Altitude Mapping Orbit (HAMO) have been processed by DLR to produce photometrically corrected monochrome and color mosaics. The photometrically corrected HAMO mosaic (Fig. 3, bottom) has been used to observe albedo variations (Schröder et al., 2017).

Fig. 4 shows the enhanced color composite image mosaic obtained by combining ratios of the seven channels available from the HAMO FC image mosaic. The color composite image ' $R$ ' (CCR) of Fig. 4 has the Red channel as $965 / 750 \mathrm{~nm}$, Green channel as $550 / 750 \mathrm{~nm}$, and Blue channel as $440 / 750 \mathrm{~nm}$. This CCR map highlights younger materials at Ceres as being more bluish than surrounding ones (Stephan et al., 2017; Jaumann et al., 2016).

We measured crater size-frequency distributions (CSFD, Fig. 5) using model ages determined from cumulative crater plots in CraterStats version 2.0 software (Michael et al., 2016). Since the surface of Ceres is broadly affected by secondary craters we implemented randomness analysis in our measurements to detect clustering/ordering of the craters' spatial distribution (Michael et al., 2012; see supplementary material for the detailed graphs). Craters for the CSFD analysis have been mapped within the Geographic Information System (GIS) used for our mapping work. The CraterTools 2.1 ESRI's ArcMap plugin (Kneissl et al., 2011) was used to map craters and produce files for CraterStats. Apart using the ESRI's ArcMap GIS software, we have worked with a parallel GIS environment based on the OSGeo Open Source software stack (Steininger and Bocher, 2009). Within this framework we updated the source code of a QGis plugin for cratercounting (Circle-Craters, Braden (2015)) to work with the QGis version 2.8 and the CraterStats version 2 (Michael, 2016). The improvements made to the original Circle-Craters software are described in the supplementary material and have been published through a Git version 


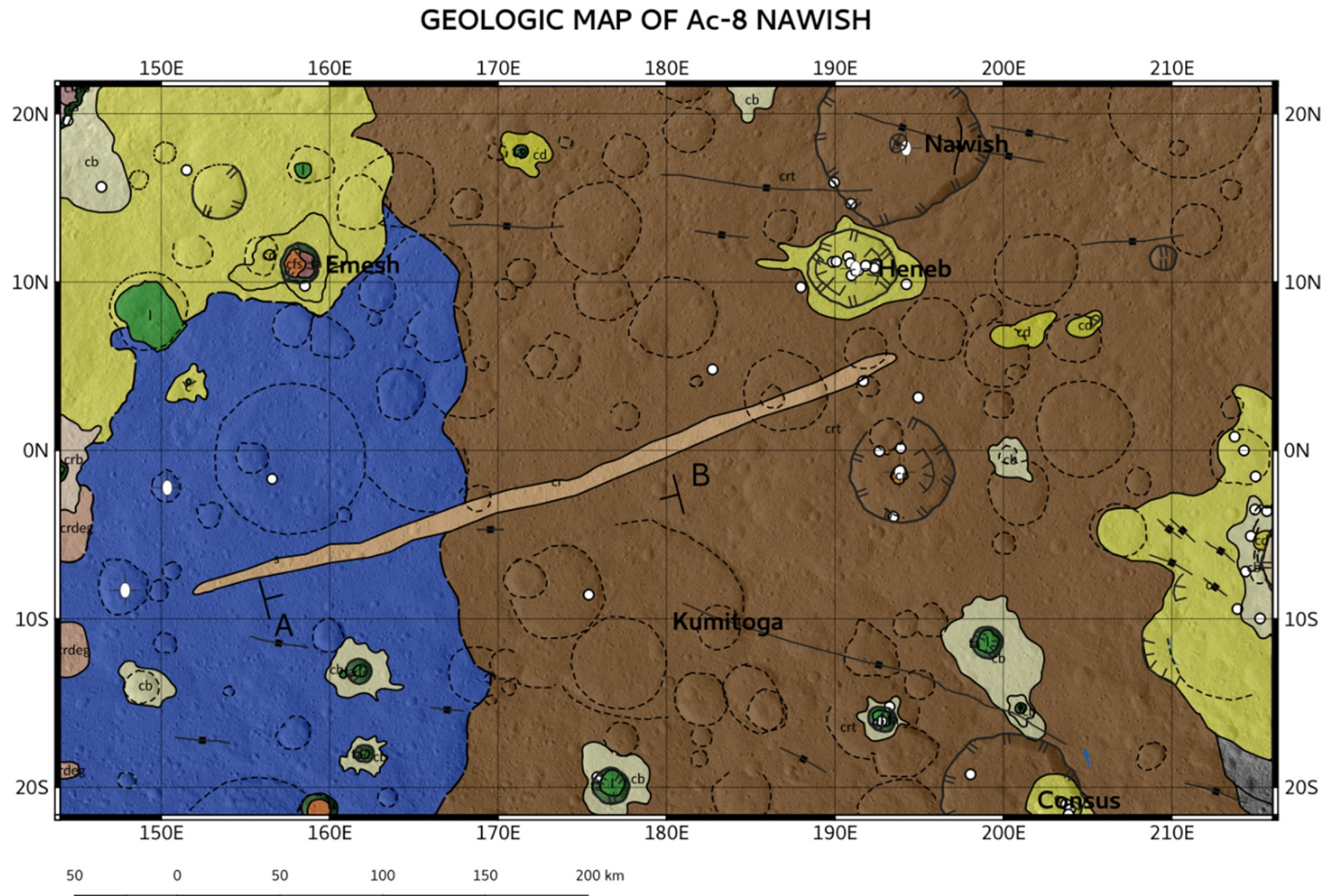

\begin{tabular}{|c|c|}
\hline \multirow[b]{2}{*}{ LINEAR FEATURE } & \multirow{2}{*}{$\begin{array}{l}\text { GEOLOGIC CONTACT } \\
- \text { accurate }\end{array}$} \\
\hline & \\
\hline ---- degraded impact crater rim & --- approximate \\
\hline ---- lineament & POINT FEATURE \\
\hline — normal fault, accurate & 0 bright spot \\
\hline Пा scarp & -0 - central peak \\
\hline$\rightarrow$ pit chain & - central pit \\
\hline fracture & \\
\hline$\Pi$ raised rim & \\
\hline$\longrightarrow$ ridge axis & \\
\hline -..-.. buried impact crater rim & \\
\hline
\end{tabular}

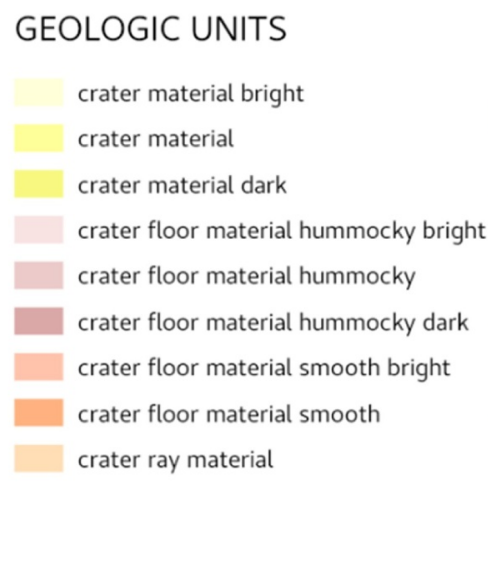

crater ray material bright

cratered terrain

lobate material

lobate material dark

smooth material

talus material

crater central peak material

crater terrace material

crater terrace material bright

crater terrace material dark

crater rim material degraded

Fig. 6. Geologic map of Nawish quadrangle. The geologic units are partially transparent over the LAMO image mosaic. Scale for displaying this figure is approximately 1:2.5 M, but digital mapping has been done at 1:500k. Projection is Equidistant Cylindrical, the scale bar is true at the equator.

control system on a publicly available collaborative platform (Perkel, 2016). Our CFSD analysis resulted in the estimation of absolute model ages following the Lunar Derived Model (LDM) adapted to Ceres (Hiesinger et al., 2016).

\section{Results}

Our geologic map of Nawish is presented in Fig. 6 and the correlation of map units is reported in Fig. 7. While the mapping scale has 


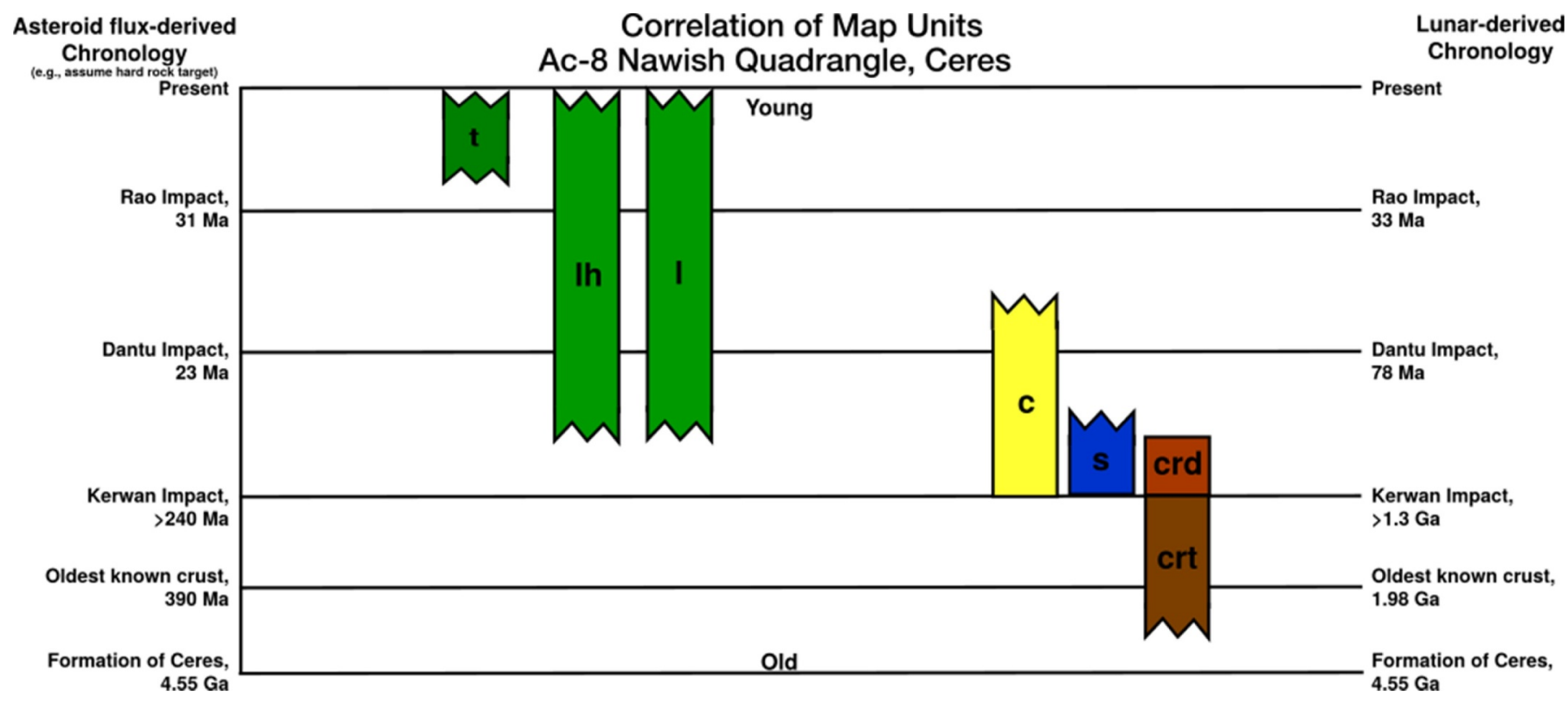

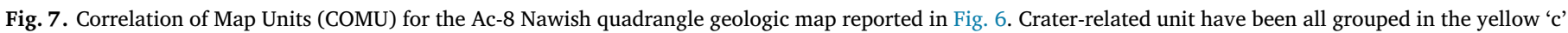
unit. (For interpretation of the references to colour in this figure legend, the reader is referred to the web version of this article.)

been set at 1:500,000 for mapping of features and geologic units, the map reported in Fig. 6 is displayed at a smaller scale to be displayed in this paper.

\subsection{Description of mapped units}

\subsubsection{Cratered terrain (crt)}

The cratered terrain unit dominates the highlands portion of Nawish quadrangle. This unit is densely cratered with craters at all diameters (Fig. 8a). The morphology of the craters varies from large craters with degraded rims (Fig. 8a, black arrow) to small craters with more prominent rims (Fig. 8a, white arrow).

The photometrically corrected mosaic of Fig. 3 (bottom) shows that this unit tends to have a lower albedo compared with the units in the western part of the quadrangle. There is a good spatial correlation also with data derived from the VIR mapping spectrometer (De Sanctis, 2010). In fact, this difference in albedo across the quadrangle is even more evident in the 1.2- $\mu \mathrm{m}$ reflectance map of Ciarniello et al. (2017) and detailed for Nawish in Carrozzo et al. (under review 2018). The distribution of this unit has also a good spatial correlation with the distribution of the band depth at $3.1 \mu \mathrm{m}$ - with lower (shallower) values in the crt unit and higher (deeper) values in the western units (Ammannito et al., 2016; see Fig. 5 in Carrozzo et al. (2018)).

Because this unit is heavily cratered, and it never superposes other units, we interpret the cratered terrain as the oldest unit in the quadrangle. Age determination through crater counting suggests an age of about $2.5 \mathrm{Ga}$ (Fig. 5 blue symbols, see the supplementary material for absolute model ages estimates). Cratered terrain has been mapped across much of the surface of Ceres with similar description of surface characteristics in other quadrangles (i.e., Williams et al., 2018a, Kerwan paper; Scully et al., 2018; Crown et al., 2018; Buczkowski et al., 2018).

Interpretation: The heavily altered upper surface crust of Ceres, modified by superposed impact materials. It is the oldest geologic unit of Ceres.

\subsubsection{Smooth material (s)}

The smooth material unit characterizes the southwestern part of the quadrangle. The type area for this unit is located within the floor of the large Kerwan basin, which has been mapped in the neighboring Ac-H-7 Kerwan quadrangle (Williams et al., 2018a, Kerwan paper). The morphology resembles the crt unit, except that it has lower abundance of craters larger than $15 \mathrm{~km}$ diameter. The crater morphologies range from very degraded for the larger craters to less degraded for the smaller ones. However, the crater size-frequency counts demonstrate that this unit is younger than the crt (Fig. 5, green symbols in the crater cumulative chart), with an age of about $1.1 \mathrm{Ga}$. Moreover, the unit appears brighter than the cratered terrain in the photometrically corrected mosaic (Fig. 3 bottom). We have mapped the contact as approximate, because it is very difficult to locate a clear contact between the smooth unit and the crt. The location of the contact has been defined by: 1) limit of crater density domain of Fig. 5 and 2) the topography changes between the western Nawish lowlands and the central Nawish highlands, as shown in the topographic profile of Fig. 9. Interpretation: Material emplaced after the large impact event which formed the Kerwan basin. (see context in Fig. 2 and details on the smooth unit in the paper of Williams et al., 2018a, Kerwan paper).

\subsubsection{Crater ray material (crm)}

The CRC map of Fig. 4 shows a linear, elongated area that is radial to the center of $92 \mathrm{~km}$ diameter Occator crater in the neighboring Occator and Ezinu quadrangles (Buczkowski et al., 2018; Scully et al., 2018). Although this feature is detectable only in the color composite map, we decided to include it in the map as it supports the interpretation of the sequence of events. It overlies both the $\mathrm{crt}$ and $s$ units. Interpretation: A bright crater ray from Occator crater (see Buczkowski et al., 2018).

\subsubsection{Crater material (c, $c b, c d)$}

We have mapped several instances of crater material which superposes either the older crt or the smooth units. Crater materials overlie/ 

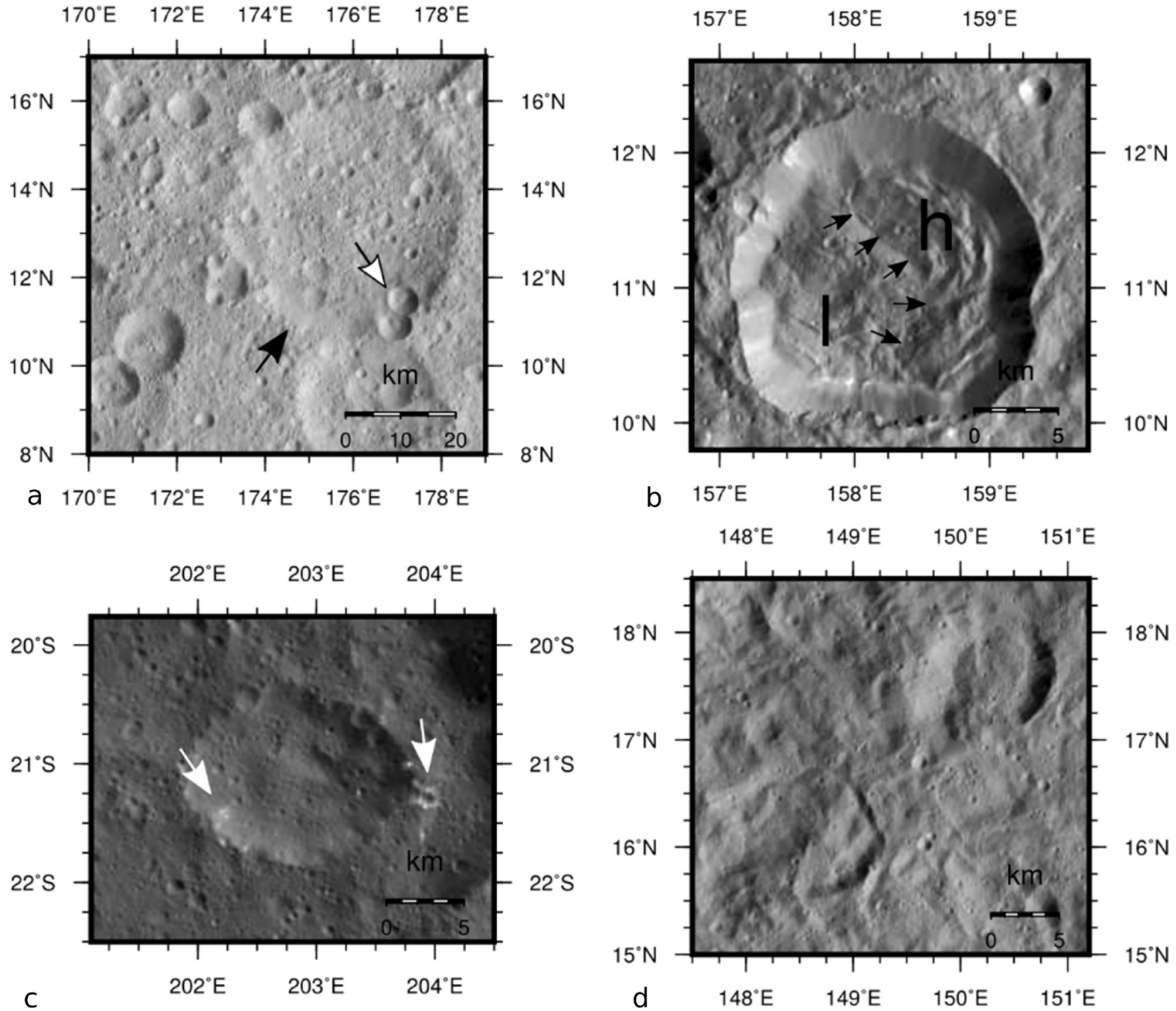

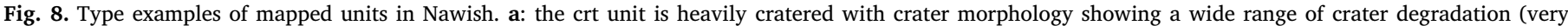

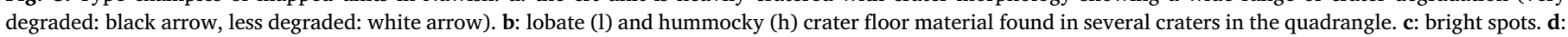
crater material filling two $10 \mathrm{~km}$ wide craters. All the images are extracted from the LAMO Framing Camera image mosaic at $35 \mathrm{~m}$ per pixel (Fig. 3 , top).

\section{Profile A-B}

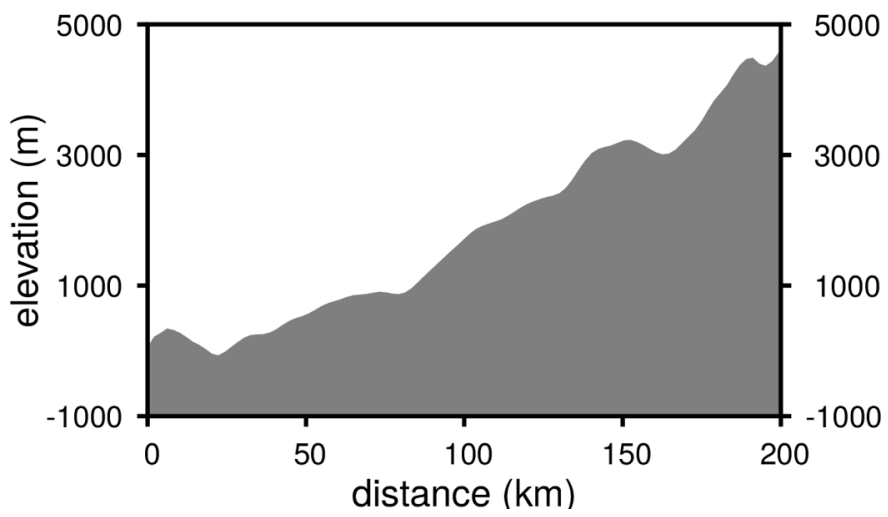

Fig. 9. Topographic profile A-B (see profile marks reported on the geologic map of Fig. 6) across the contact between the smooth unit (s) and the cratered terrain (crt). fill previous topography and appear smooth at LAMO scale, as shown in Fig. 8d, where the crater material comes from Dantu (quadrangle Ac-3). Fig. 10 shows the contrast in texture and crater density between the crater material and the old cratered terrain material. The CRC image of sub-panel of Fig. 10 shows that materials are bluish, indicating the fresh impact (Stephan et al., 2017).

At the eastern border of the quadrangle, the crater material is related to the Azacca and Nepen craters of the Ac-9 quadrangle (see Buczkowski et al., 2018) while the crater material at north-west is related to Dantu (See Williams et al., 2018a, Kerwan paper).

We mapped crater bright $(c b)$ and crater dark $(c d)$ materials, on the basis of the albedo variation of these materials in relation to their surroundings This supports the idea that bright and dark materials have limited lateral extents in the shallow cerean crust, and impacts can excavate both these materials. Interpretation: Materials emplaced by impacts into the cerean crust, including ejecta blankets and some exposures of crater rim and floor materials. 


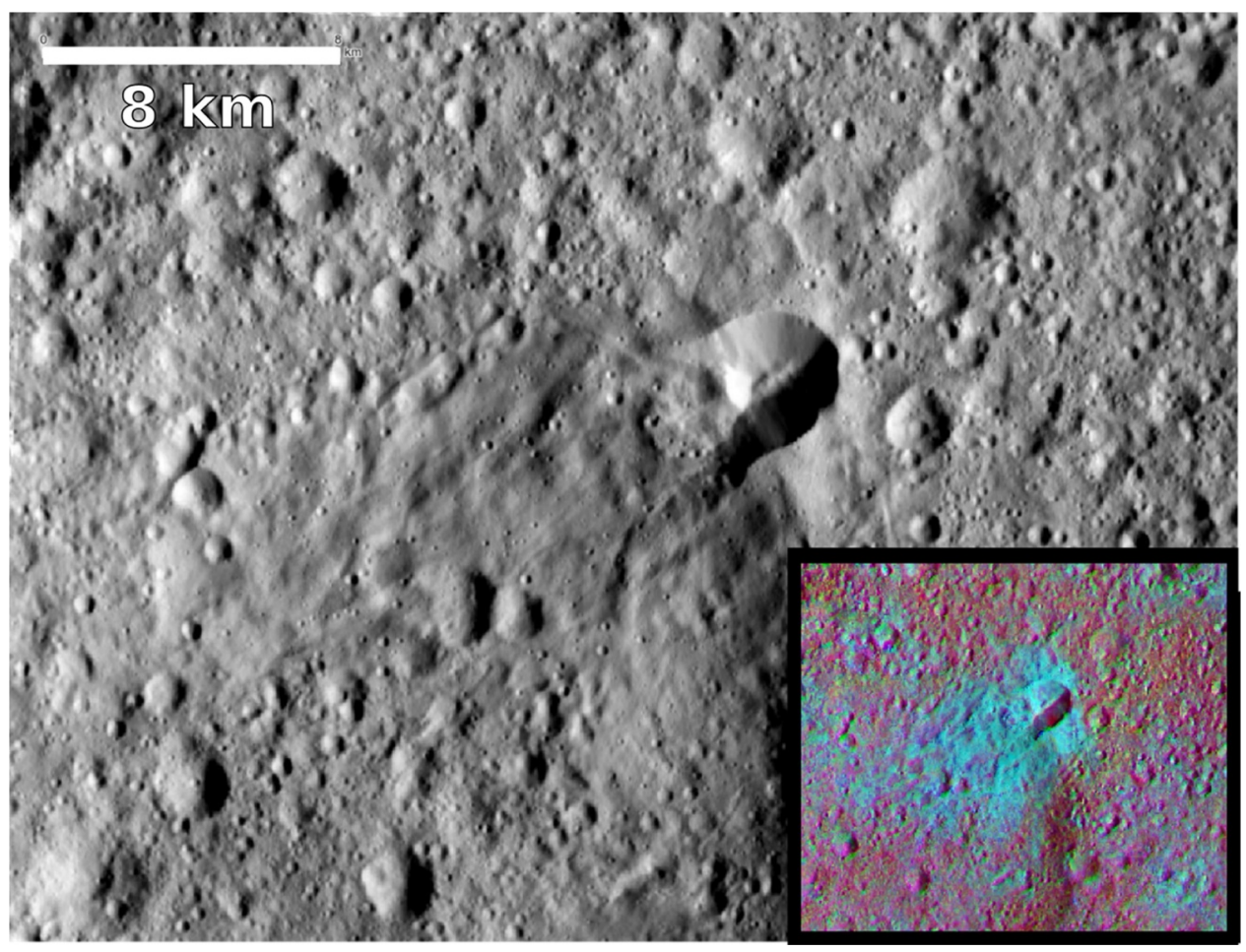

Fig. 10. An example of the effect of a fresh impact crater centered at 205.55E, 7.80 N. The impact occured on the border of a degraded crater causing an asymmetrical distribution of the ejecta. The ejecta blankets distributed downslope at south-west appear darker than the ones ejected at north-east, but this can be attributed to illumination condition. The subfigure shows the same feature seen on the HAMO CC'R' map of Fig. 4: all the material excavated and emplaced by the impact event appear bluish. (For interpretation of the references to colour in this figure legend, the reader is referred to the web version of this article.)

4.1.5. Crater-related lobate and hummocky materials (l,lh)

These units have been mapped on some crater floors of Nawish quadrangle. In particular all the craters with talus material on the walls have lobate / hummocky materials on their floor. The morphology is characterized by lobes and mounds (Figs. $8 \mathbf{b}$ and 11). Interpretation: Material mobilized by gravity from the crater walls and accumulated by mass wasting processes as a consequence of the impact which formed the crater and/or subsequent shaking. Albedo variations are consistent with the material around the crater.

\subsubsection{Talus material ( $t$ )}

Talus material is a smooth unit with almost no craters on it and constitutes the walls of some complex craters. Fig. 11 shows the typical example of talus material on an $18 \mathrm{~km}$-wide crater. Talus material has always a contact in common with the lobate or the hummocky crater floor materials. Interpretation: Material from impact crater walls and rims that is the source of material for lobate and hummocky materials on the crater floors.

\subsection{Relevant features}

\subsubsection{Bright spots}

Fig. 8c shows a bright spot within Nawish. We have mapped bright spots as point features, indicative of small areas with an albedo value greater than 0.065 in the photometrically corrected image mosaic (Fig. 3 bottom). This value is arguably greater than surroundings (Stein et al., 2017) and greater than the average albedo of Ceres (Thangjam et al., 2018). Clusters of bright spots are present on crater Heneb's floor and in the Azacca and Dantu crater materials. The spatial distribution of the bright spots shows that these features are mostly

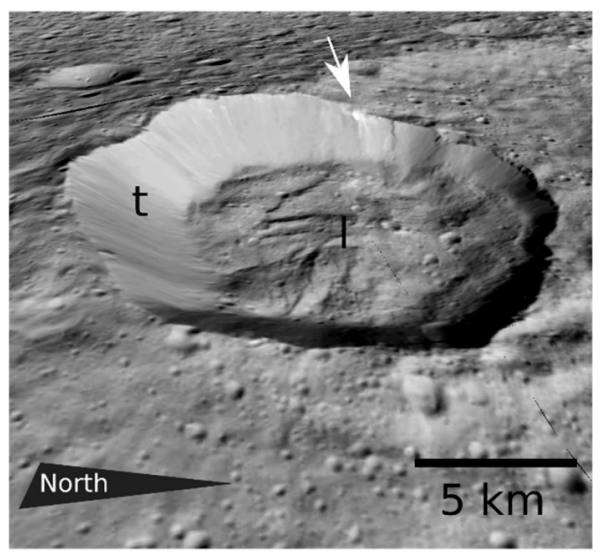

Fig. 11. Perspective view of the $18 \mathrm{~km}$-wide crater centered at 176.72E 19.87S. The crater has sharp rims and the crater walls show talus material $(\mathrm{t})$ from the rim downwards. On the western sector, the talus material superposes the lobate material (l) of the crater floor. The white arrow indicates a bright spot next to the crater rim.

associated with impact craters.

In addition, all the bright spots we have mapped are spatially correlated with a bluish tone of the CRC map of Fig. 4, although not all the bluish material has bright spots. The possible explanation is that the distribution of the source of bright spots is not even across the quadrangle or that the bright spots lose their albedo over time (Palomba et al., 2017). 

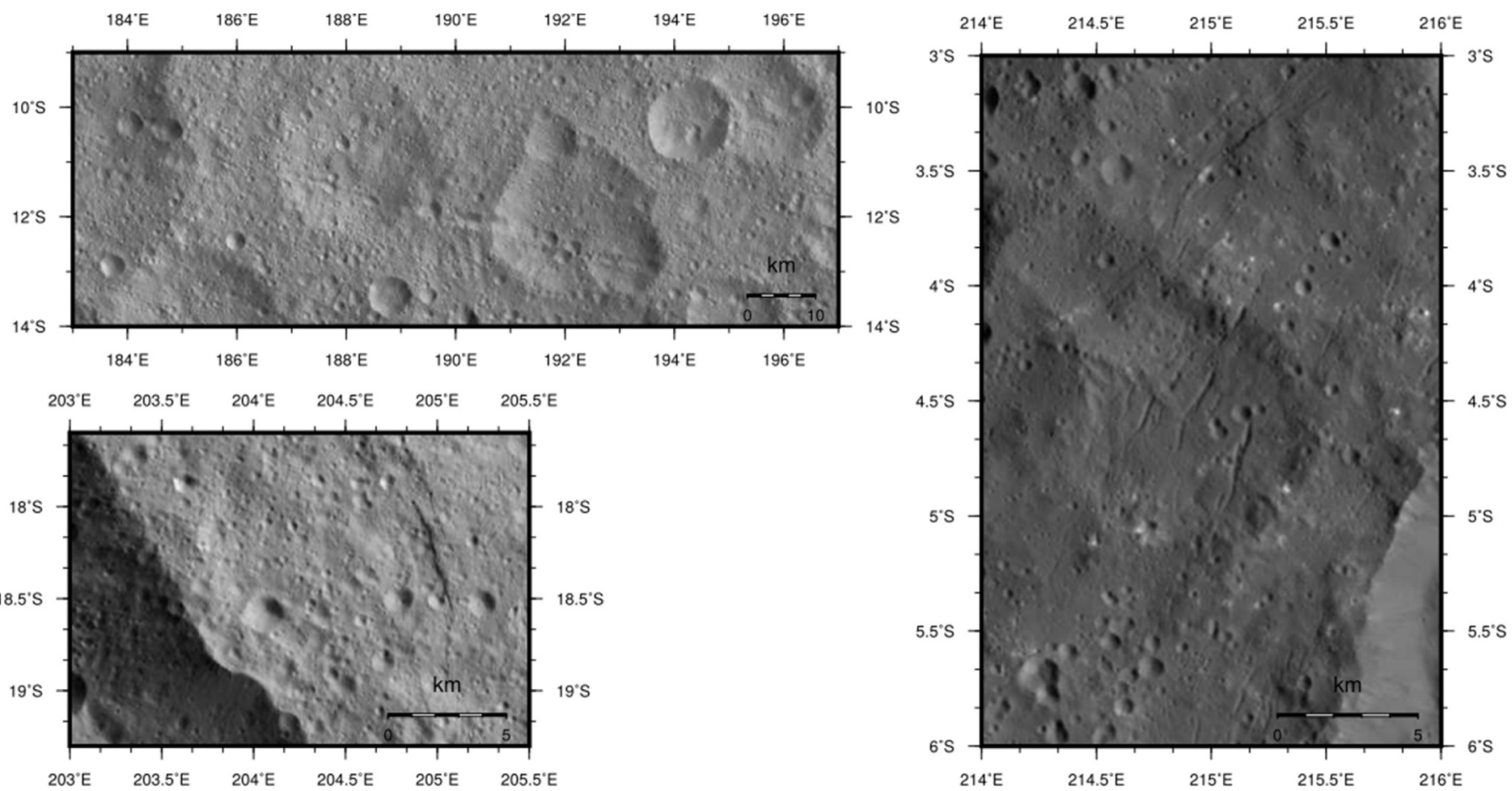

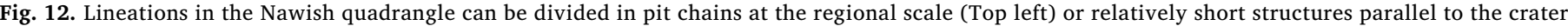

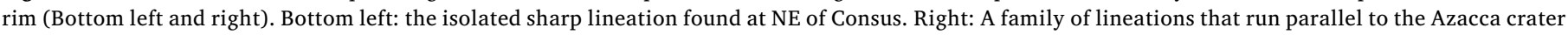
rim.

\subsubsection{Linear features}

Within Nawish quadrangle we identified two groups of linear features. One group is made up of secondary crater chains 20 to $150 \mathrm{~km}$ long with a width up to $3 \mathrm{~km}$, with a direction varying from E-W to NWSE (Fig. 12, top-left). These features show furrows and circular depressions that are not radial to craters in the Nawish quadrangle. Rather, simulations show that they fit to the pattern of ejecta coming from impacts craters outside of Nawish, especially those found in the northern part of the quadrangle (see e.g., Scully et al., 2017; Crown et al., 2018).

The other group of lineation is much shorter and associated with two of the impact craters in the study area. Fig. 12 bottom-right shows a very sharp $5 \mathrm{~km}$ long lineation that runs parallel to the north eastern rim of crater Consus. Fig. 12 right, shows a family of lineation 1 to $3 \mathrm{~km}$ long and up to $250 \mathrm{~m}$ wide, parallel to the rim of Azacca craters. We interpret the sharp morphology of the lineation next to Consus as the expression of an extensional fracture with the footwall on the western side. The lineation associated with Azacca are interpreted as pit chains related to underlying extensional fractures generated by the collapse of the crater walls.

\subsubsection{Central peaks, central pits, main craters morphology}

We mapped central peaks and pits as point features and terraces, degraded/pristine rims as line features. We mapped five central peaks within craters from 15 to $80 \mathrm{~km}$ of diameter.

We analyzed the topography of three craters that show a wide range of internal crater features. Fig. 13 shows the morphology and the topographic profiles across three of the main craters in the Nawish quadrangle, isolated from the whole topographic map. These craters are, from north southwards, the $80-\mathrm{km}$ wide Nawish crater, the $42-\mathrm{km}$ wide Heneb crater and an unnamed $50-\mathrm{km}$ wide crater centered at 193.8E 1.49S. The A-B profile across Nawish shows a $20-\mathrm{km}$ wide central peak with a $8 \mathrm{~km}$ wide pit depression on it. From the details of the morphology shown in the subpanel of Fig. 13, we see that the peak structure is preserved only on the eastern and western side of the pit. The peak's top is about $1000 \mathrm{~m}$ above the crater's floor while the deepest point of the top lies $1 \mathrm{~km}$ below the crater's floor. The shape of Nawish crater is far from being circular. We interpret the rectification of part of the crater rim as the effect of mass wasting processes that mobilize material from the walls of the crater and accumulate it on its floor.

The C-D profile of Fig. 13 across Heneb shows a $5 \mathrm{~km}$ wide and about $500 \mathrm{~m}$ high central peak with no pit on it, and terraces on both side of the profile about $1000 \mathrm{~m}$ lower than the craters' rim.

The topographic profile E-F of Fig. 13 across the unnamed crater at 193.8E $1.49 \mathrm{~S}$ features a prominent $20 \mathrm{~km}$-wide central peak rising $1500 \mathrm{~m}$ from above the crater's floor. Profile E-F also shows a change of inclination of the slope of the crater walls at about $1200 \mathrm{~m}$ below the crater's rim.

The central peak with an associated pit on it in Nawish crater is typical of large ( $>60-70 \mathrm{~km}$ ) craters on Ceres, as for example the 92$\mathrm{km}$ wide Occator (Schenk et al., 2018, in prep.), and is interpreted as the result of the presence of some percentage of ice in the target material (Hiesinger et al., 2016; Elder et al., 2012).

Nawish, which is the largest of the three, exhibits a central pit on the central peak, while the middle sized one has a central peak with no 

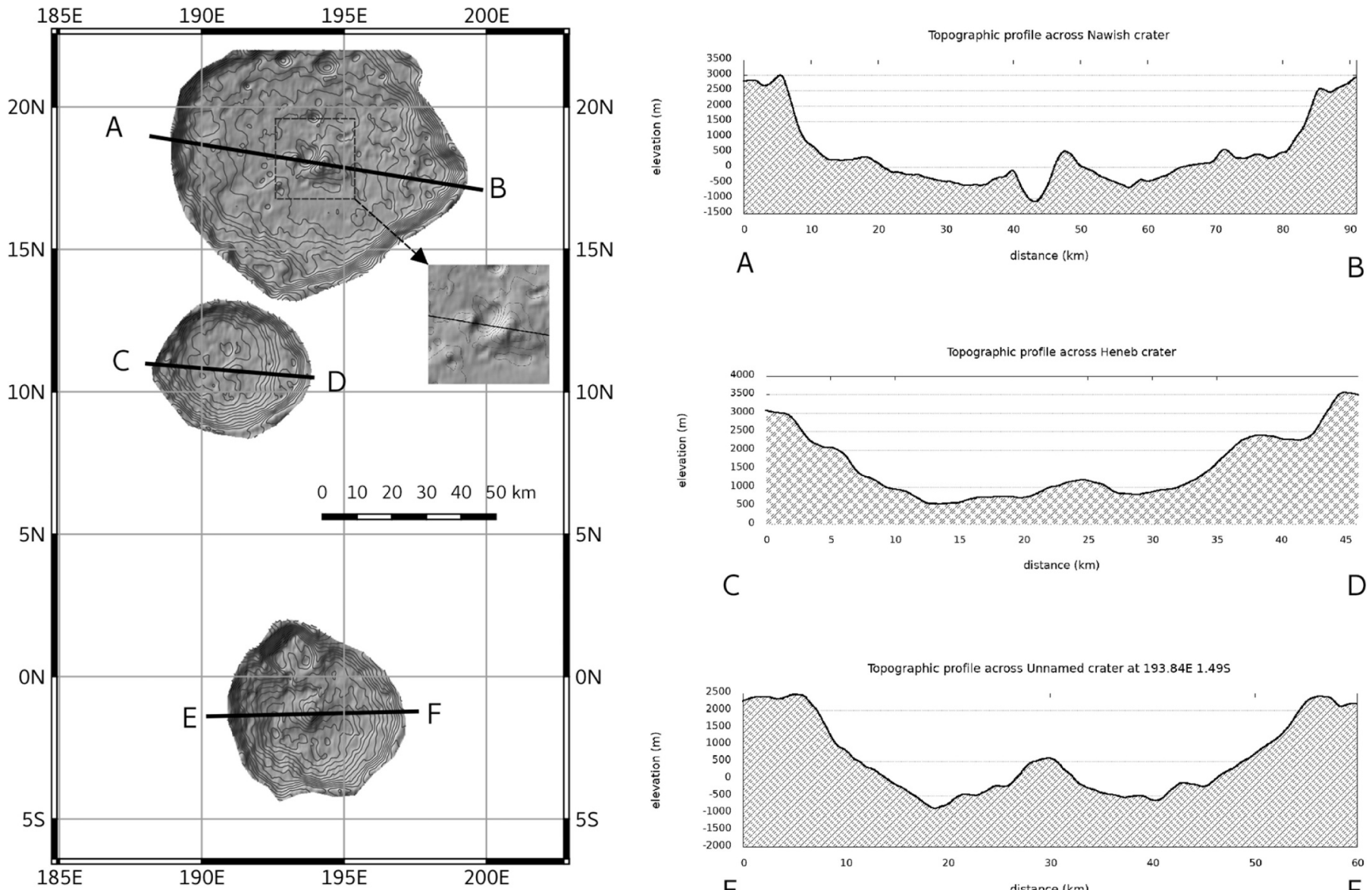

C

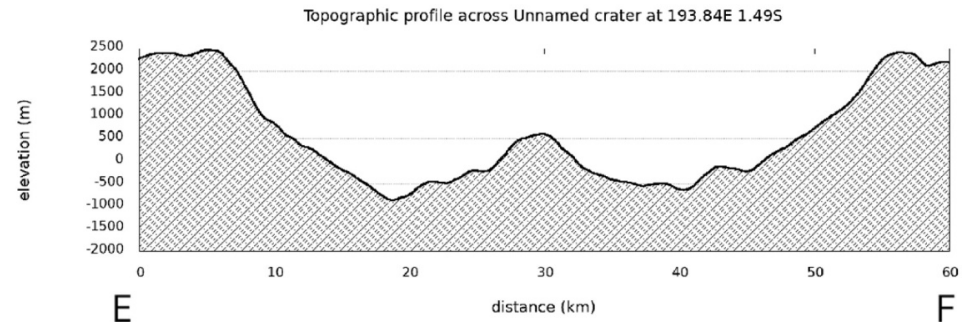

Fig. 13. Morphology of the three main craters of Nawish quadrangle that show central peaks, pits and terraces. On the left, map view of Nawish, Heneb and an unnamed crater. The shaded relief shows the morphology of the craters and the 250-meter gray isolines assist in evaluating elevation changes; the zoomed area indicated by the arrow is located within the dashed frame and shows details of the morphology of the central peak of Nawish. On the right, the topographic profiles across the craters are reported with references to the location of the profile traces in the map view. Along profile A-B through the $80 \mathrm{~km}$-wide Nawish crater, it is evident a $1 \mathrm{~km}$ high central peak with a central pit which at its deepest point is $1 \mathrm{~km}$ lower than the crater floor. Profile C-D through Heneb Crater shows terraces on both sides about $1 \mathrm{~km}$ lower than the crater's rim. The center of the crater features a $500 \mathrm{~m}$ high central peak. The profile across the $50 \mathrm{~km}$-wide unnamed crater centered at 193.84E $1.49 \mathrm{~S}$ shows a prominent central peak structure rising up to $1.5 \mathrm{~km}$ above the crater floor.

pit, and the smaller Heneb has a just barely detectable central peak. The other two smaller craters of Fig. 13 have central peaks but no pits; we interpret these three craters as the expression of three different stages of complex crater formation on the basis of the diameter / energy involved (Melosh, 1996, 2011).

\section{Discussion}

Within this work we have mapped a variety of crater-related units from ancient cratered terrain to Kerwan smooth material (Williams et al., 2018a, Kerwan paper) to ejecta of younger superposed craters. However, when we compare map units and topography, we do not identify a single principal feature that has driven the geologic evolution of the quadrangle. Instead, we recognize several elements which delineate the geology of the study. The topography within Nawish quadrangle spans $9700 \mathrm{~m}$, which alone represents $67 \%$ of the whole topographic variation over Ceres. The anti-correlation between topography and the Bouguer anomaly from the gravity data indicates that there is isostatic compensation across the area, and thus this topographic signature is not likely to be the effect of recent tectonics (see Bouguer anomaly map of Nawish in supplementary material). Lowpass filtering of the topography at the global scale made by Hiesinger et al. (2016) shows that two large, ancient depressions are present on Ceres, in agreement with the study of Marchi et al. (2016) who proposed that one of these two, Vendimia Planitia, is a large, ancient impact basin that predates the Kerwan impact. Fig. 14 shows a global view of Ceres with the center of the Vendimia Planitia depression (black cross) and trace its limits. Nawish quadrangle (dashed line in Fig. 14) contains the edge of the Vendimia Planitia basin where it appears to be most well preserved. In order to detect the structure of the impact basin within Nawish quadrangle we analyzed the topographic data similarly to Marchi et al. (2016). We traced 18 topographic profiles, covering a total distance of $14,400 \mathrm{~km}$, each one of them beginning from the center of the putative Vendimia basin (135E $20 \mathrm{~N}$, black 


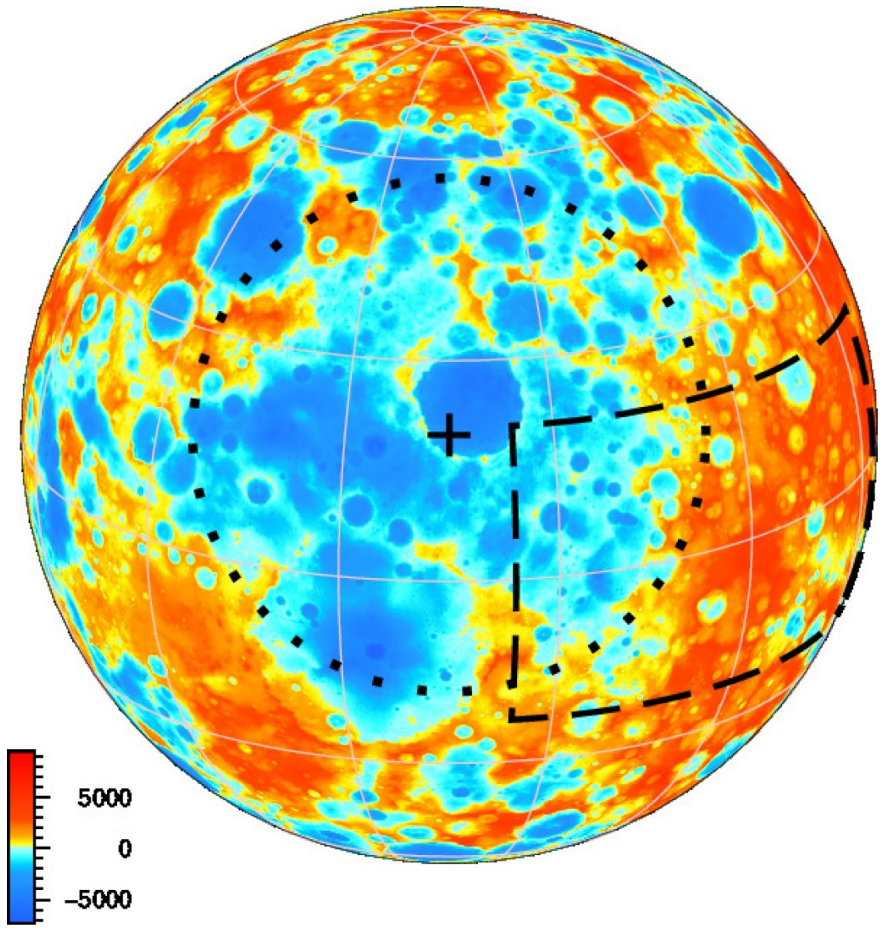

Fig. 14. Topography of Ceres with the location of the basin of Vendimia Planitia, elevation is in meters. The cross symbol represents the basin's center at $135 \mathrm{E} 20 \mathrm{~N}$, while the dotted line is the limit of the basin. Black dashed lines represent the boundaries of Nawish quadrangle. Color scale represents elevation in meters.

cross of Fig. 14), constructing profiles every $5^{\circ}$ from azimuth $85^{\circ}$ to $175^{\circ}$, spanning the Nawish quadrangle. In Fig. 15, the red line shows the mean topographic profile resulting from the 18 separate profiles. The trend of the red profile highlights the structure of a large depression from its center to the distal reaches, with a raised rim at about $420 \mathrm{~km}$ from the center. We interpret the red line of Fig. 15 as evidence that part of the floor, wall, and remnant rim of the Vendimia Planitia impact basin exist within the Nawish quadrangle.

The central and eastern highlands are characterized by the $2.5 \mathrm{Ga}$ old cerean crust, i.e., the cratered terrain. The western lowlands, which have negative elevations, are geologically different and represent the interior of the large, ancient Vendimia Planitia basin.

The southern lowlands are characterized by the Kerwan smooth material, which are the melted products of the Kerwan impact (Williams et al., 2018a, Kerwan paper), that have propagated radially and partly filled the Vendimia Planitia basin interior, where its emplacement was contained by the Vendimia wall/rim. The mineralogic data (Ammannito 2016; Carrozzo et al., 2018 in press) also show a westward trend of increasing band absorption values for the $3.1 \mu \mathrm{m}$ band, meaning that the western lowlands terrains are characterized by a higher abundance of ammonia-bearing phyllosilicates compared to the older highlands. Thus, we propose that the Kerwan smooth material represents evidence of ancient hydrothermal rock-water interaction that can occur at low temperatures (Levinson and Day, 1968). Recent experimental research proposed by Neveu et al. (2017) shows that ammoniation of clays preferentially occurs at temperatures lower than $50^{\circ}$ Celsius.

The northern lowlands show a portion of Dantu crater and its ejecta, which is bluish in the CRC mosaic (Fig. 4). The crater material of the northern lowlands fills almost completely the pre-existing smooth material topography and has a crater size-density distribution that shows the effect of the resurfacing process (red symbols on CFSD chart of Fig. 5; Michael and Neukum (2010); Michael (2013); see supplementary material for a detailed graph).

\section{Conclusions}

This geologic mapping of the Nawish quadrangle enabled the identification of the evolution of the area, synthesized in the geologic map of Fig. 6 and the correlation of the map units of Fig. 7. Applying crater frequency-size analysis to our map units, we have determined that the oldest material, the cratered terrain, is about $2.5 \mathrm{Ga}$ old, in agreement with similar measurements made globally or locally in other quadrangle-based geologic analysis. The topography of the area can be divided into a highlands region in the east and a lowlands region in the west. The analysis of the topography correlates with the putative Vendimia Planitia impact basin (Marchi et al., 2016), which overlaps partly with this quadrangle. We interpret the topographic variation that separates the lowlands and the highlands as the rim of the $830 \mathrm{~km}$ wide Vendimia Planitia basin, which impacted Ceres in its early history and whose topography is still detectable at the global scale (Hiesinger et al., 2016; Marchi et al., 2016).

The second oldest geologic unit in the Nawish quadrangle is the 1.1 Ga-old Kerwan smooth material (the smooth unit), which is composed of melted cerean crust rich in ammonia that formed as result of the Kerwan impact (Williams et al., 2018a, Kerwan paper), and which is superposed to the floor of the Vendimia Planitia basin. This smooth unit has covered the cratered terrain and fills the lowlands, up to the base of the slope separating the highlands, presumably the remnants of the Vendimia basin rim. The northern sector of the lowlands shows extensive crater materials emplaced on top of the Kerwan smooth material, coming from the Dantu crater.

Superposed on these regional units we have mapped younger craterrelated units emplaced by recent impacts. These craters show sharp rims, talus materials on the crater walls, and floors occupied by lobate and occasionally hummocky materials. The lobate shape of the deposits on the crater floors suggests that the presence of ice could have driven the mechanics of the emplacement of these materials (e.g., Hughson et al., 2018).

The spatial distribution of bright spots within Nawish is spatially related to fresh crater-related materials. However, not all the fresh craters of similar size in Nawish quadrangle have the presence of bright spots, indicating that the distribution of bright materials (e.g., salts De Sanctis et al., 2016) within the Cerean crust is not laterally continuous.

Linear features in Nawish quadrangle can be divided into those that occur on a regional scale and those on a local scale. The regional-scale features are large secondary crater chains and pit chains related, respectively, to secondary cratering and the collapse of material into large fractures. Simulations presented in Scully et al. (2017) and Crown et al. (2018) show that the direction of the regional-scale secondary crater chains in the north of the quadrangle are comparable with the effect of secondary cratering from the Urvara and/or Yalode impact events. In contrast, local-scale linear features are associated with much smaller individual impact craters.

We conclude that the Nawish quadrangle represents an area of Ceres where the most ancient crust of Ceres is well preserved with the evidence of primordial crustal-scale structures and coexists with impact materials from very recent geologic events. 


\section{radial topographic profiles}

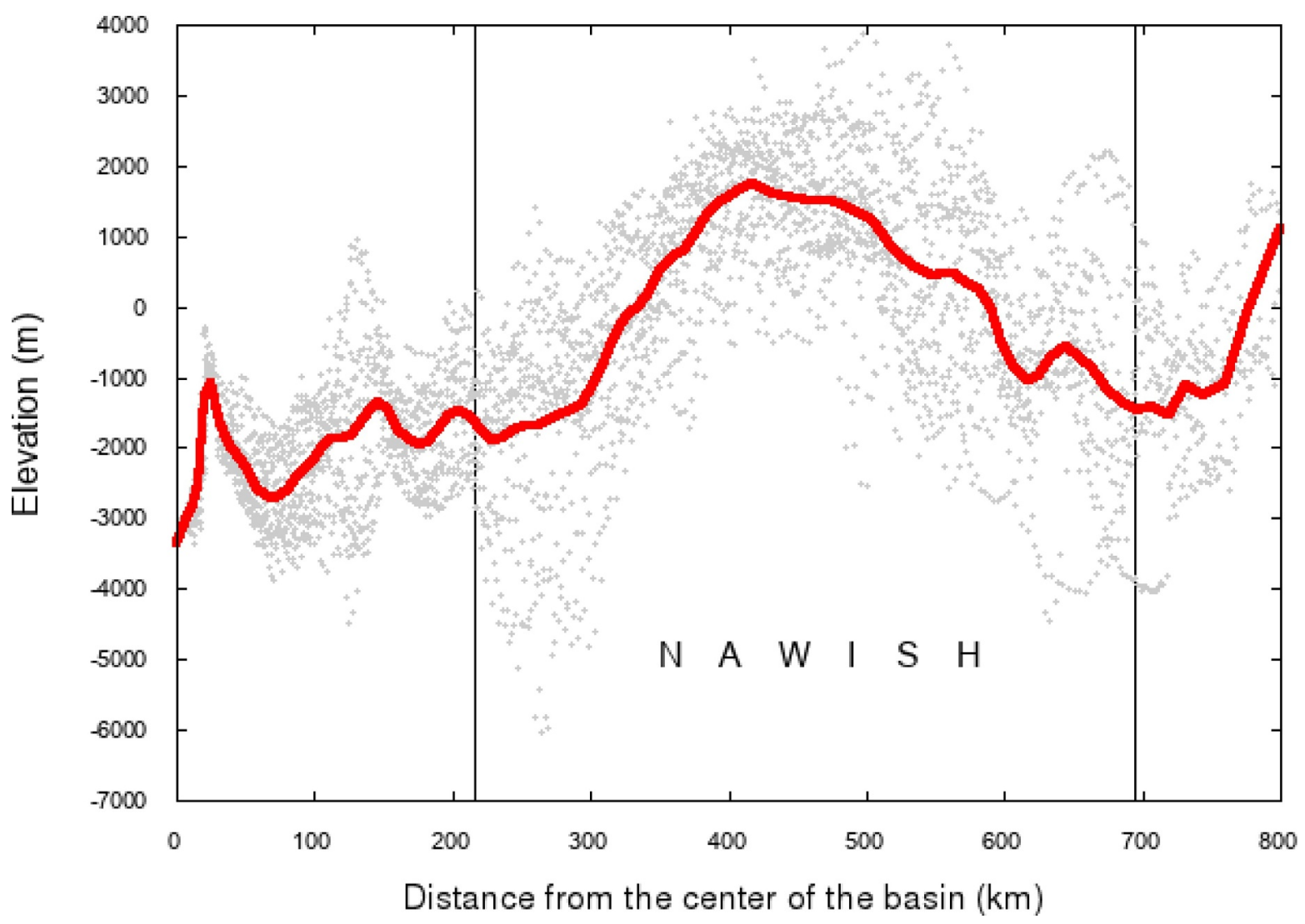

Fig. 15. The red line shows the mean radial profile departing from the center of Vendimia Planitia basin towards Nawish quadrangle. The mean is obtained from 18 , $800-\mathrm{km}$ long profiles (grey dots are the elevation points sampled along the profiles) departing from point 135E $20 \mathrm{~N}$ (black cross in Fig. 14) and spaced $5^{\circ}$, from azimuth $85^{\circ}$ to azimuth $175^{\circ}$, passing throughout Nawish quadrangle (vertical black lines indicate approximately the borders of the quadrangle). The shape of the mean profile shows clearly that the big Vendimia Basin has a well defined rim at about $415 \mathrm{~km}$ from its center. (For interpretation of the references to colour in this figure legend, the reader is referred to the web version of this article.)

\section{Acknowledgements}

The funding for this research was provided by Italian Space Agency (ASI) through grant number I/004/12/0.Some co-authors were funded under NASA contract NNM05AA86 for the Dawn Discovery Mission. Authors also thank the NASA Dawn Science and Flight Teams at the Jet Propulsion Laboratory and the Instruments' teams for delivering the dataset used in this study. The lead author is grateful to co-authors and colleagues who supported him in the difficult times after the loss of his father, who was always his most enthusiastic supporter, in life and work.

\section{Supplementary materials}

Supplementary material associated with this article can be found, in the online version, at doi:10.1016/j.icarus.2018.08.015.

\section{References}

Ammannito, E., De Sanctis, M.C., Ciarniello, M., Frigeri, A., Carrozzo, F.G., Combe, J.-P., Ehlmann, B.L., Marchi, S., McSween, H.Y., Raponi, A., Toplis, M.J., Tosi, F., CastilloRogez, J.C., Capaccioni, F., Capria, M.T., Fonte, S., Giardino, M., Jaumann, R. Longobardo, A., Joy, S.P., Magni, G., McCord, T.B., McFadden, L.A., Palomba, E., Pieters, C.M., Polanskey, C.A., Rayman, M.D., Raymond, C.A., Schenk, P.M., Zambon, F., Russell, C.T., 2016. Distribution of phyllosilicates on the surface of Ceres. Science
353, aaf4279.

Braden, S.E., 2015. An open source alternative for crater counting using QGIS and the CircleCraters Plugin 46th LPSC. Abstract 1816.

Buczkowski, D.L., Schmidt, B., Williams, D.A., Mest, S.C., Scully, J.E.C., Ermakov, A.E., F.Preusker, P.Schenk, Otto, K., Hiesinger, H., O'Brien, D., Marchi, S., Sizemore, H., Hughson, K., Chilton, H., Bland, M., Byrne, S., Schorghofer, N., Ruesch, O., Platz, T., Jaumann, R., Roatsch, T., Sykes, M.V., Nathues, A., De Sanctis, M.C., Raymond, C.A., Russell, C.T., 2016. The geomorphology of Ceres. Science 353 (6303) aaf4332 1-6.

Buczkowski, D., Williams, D., Scully, J., Mest, S., Crown, D., Schenk, P., Jaumann, R., Roatsch, T., Preusker, F., Nathues, A., Hoffmann, M., Schaefer, M., Marchi, S., Sanctis, M.D., Raymond, C., Russell, C., 2018. The geology of the Occator quadrangle of dwarf planet Ceres: Floor-fractured craters and other geomorphic evidence of cryomagmatism. Icarus 316, 128-139.

Carrozzo, F.G., Zambon, F., De Sanctis, M.C., Longobardo, A., Raponi, A., Stephan, K. Frigeri, A., Ammannito, E., Ciarniello, M., Combe, J.-Ph., Palomba, E., Tosi, F., Raymond, C.A., Russell, C.T., 2018. The mineralogy of the Nawish quadrangle of Ceres. Icarus. In Press: https://www.sciencedirect.com/science/article/pii/ S0019103516306868.

Ciarniello, M., De Sanctis, M.C., Ammannito, E., Raponi, A., Longobardo, A., Palomba, E., Carrozzo, F.G., Tosi, F., Li, J.-Y., Schröder, S.E., Zambon, F., Frigeri, A., Fonte, S., Giardino, M., Pieters, C.M., Raymond, C.A., Russell, C.T., 2017. Spectrophotometric properties of dwarf planet Ceres from the VIR spectrometer on board the Dawn mission. Astron. Astrophys. 598, A130.

Crown, D.A., Sizemore, H.G., Yingst, R.A., Mest, S.C., Platz, T., Berman, D.C., Schmedemann, N., Buczkowski, D.L., Williams, D.A., Roatsch, T., et al., 2018. Geologic mapping of the Urvara and Yalode Quadrangles of Ceres. Icarus 316, 167-190.

De Sanctis, M.C., Coradini, A., Ammannito, E., Filacchione, G., Capria, M.T., Fonte, S., Magni, G., Barbis, A., Bini, A., Dami, M., Ficai-Veltroni, I., Preti, G., 2011. The VIR Spectrometer. Space Sci. Rev. 163, 329-369.

De Sanctis, M.C., Raponi, A., Ammannito, E., Ciarniello, M., Toplis, M.J., McSween, H.Y., 
Castillo-Rogez, J.C., Ehlmann, B.L., Carrozzo, F.G., Marchi, S., Tosi, F., Zambon, F., Capaccioni, F., Capria, M.T., Fonte, S., Formisano, M., Frigeri, A., Giardino, M., Longobardo, A., Magni, G., Palomba, E., McFadden, L.A., Pieters, C.M., Jaumann, R., Schenk, P., Mugnuolo, R., Raymond, C.A., Russell, C.T., 2016. Bright carbonate deposits as evidence of aqueous alteration on (1) Ceres. Nature 536, 54-57.

Elder, C.M., Bray, V.J., Melosh, H.J., 2012. The theoretical plausibility of central pit crater formation via melt drainage. Icarus 221, 831-843.

Ermakov, A.I., Fu, R.R., Castillo-Rogez, J.C., Raymond, C.A., Park, R.S., Preusker, F., Zuber, M.T., 2017. Constraints on Ceres' internal structure and evolution from its shape and gravity measured by the Dawn spacecraft. J. Geophys. Res. Planets 122 $2267-2293$

Greeley, R., Batson, R.M., 1990. Planetary Mapping. In: Greeley, R., Batson, R.M. (Eds.), Cambridge Planetary Science Series. Cambridge University Press.

Hiesinger, H., Marchi, S., Schmedemann, N., Schenk, P., Pasckert, J.H., Neesemann, A., O'Brien, D.P., Kneissl, T., Ermakov, A.I., Fu, R.R., Bland, M.T., Nathues, A., Platz, T., Williams, D.A., Jaumann, R., Castillo-Rogez, J.C., Ruesch, O., Schmidt, B., Park, R.S., Preusker, F., Buczkowski, D.L., Russell, C.T., Raymond, C.A., 2016. Cratering on Ceres: Implications for its crust and evolution. Science 353 pp. aaf 4758.

Hughson, K.H., Russell, C., Williams, D., Buczkowski, D., Mest, S., Pasckert, J., Scully, J., Combe, J.-P., Platz, T., Ruesch, O., Preusker, F., Jaumann, R., Nass, A., Roatsch, T, Nathues, A., Schaefer, M., Schmidt, B., Chilton, H., Ermakov, A., Singh, S., McFadden, L., Raymond, C., 2018. The Ac-5 (Fejokoo) quadrangle of Ceres: geologic map and geomorphological evidence for ground ice mediated surface processes. Icarus 316, 63-83.

Jaumann, R., Stephan, K., Krohn, K., Matz, K.-D., Otto, K., Neumann, W., Kneissl, T., Schmedemann, N., Schroeder, S., Tosi, F., De Sanctis, M.C., Preusker, F., Buczkowski, D., Capaccioni, F., Carsenty, U., Elgner, S., von der Gathen, I., Gieber, T., Hiesinger, H., Hoffmann, M., Kersten, E., Li, J.-Y., McCord, T.B., McFadden, L., Mottola, S., Nathues, A., Neesemann, A., Raymond, C., Roatsch, T., Russell, C.T., Schmidt, B., Schulzeck, F., Wagner, R. \& Williams, D.A., 2016. Age-dependent morphological and compositional variations on Ceres. In 47th LPSC abstract 1455.

Kneissl, T., van Gasselt, S., Neukum, G., 2011. Map-projection-independent crater sizefrequency determination in GIS environments, New software tool for ArcGIS. Planet. Space Sci. 59, 1243-1254.

Levinson, A.A., Day, J.J., 1968. Low temperature hydrothermal synthesis of montmorillonite. Ammonium-micas and ammonium-zeolites. Earth Planet. Sci. Lett. 5, 52-54.

Marchi, S., Ermakov, A.I., Raymond, C.A., Fu, R.R., O'Brien, D.P., Bland, M.T. Ammannito, E., de Sanctis, M.C., Bowling, T., Schenk, P., Scully, J.E.C., Buczkowski, D.L., Williams, D.A., Hiesinger, H., Russell, C.T., 2016. The missing large impact craters on Ceres. Nat. Commun. 7, 12257.

Melosh, H.J., 1996. Impact Cratering: a geologic Process. Cambridge University Press.

Melosh, H.J., 2011. Planetary Surface Processes. Cambridge University Press.

Mest, S., Crown, D., Aileen Yingst, R., Berman, D., Williams, D., Buczkowski, D., Scully, J., Platz, T., Jaumann, R., Roatsch, T., Preusker, F., Nathues, A., Hiesinger, H., Hendrik Pasckert, J., Raymond, C. and Russell, C., 2017a. The HAMO-based global geologic map of Ceres. 47th LPSC, Abstract \#11711.

Mest, S.C.,Crown, D.A., Yingst R. A., Berman D. C., Williams D. A., Buczkowski D. L., Scully J.E.C., Platz T., Jaumann R., Roatsch T, Preusker F., Nathues A., Hiesinger H., Pasckert J.H., Raymond C.A., and Russell C.T. 2017b. HAMO-based global geologic map of Ceres, Icarus, in preparation.

Michael, G.G., Neukum, G., 2010. Planetary surface dating from crater size-frequency distribution measurements: Partial resurfacing events and statistical age uncertainty. Earth Planet. Sci. Lett. 294, 223-229.

Michael, G.G., Platz, T., Kneissl, T., Schmedemann, N., 2012. Planetary surface dating from crater size-frequency distribution measurements: spatial randomness and clustering. Icarus 218, 169-177.

Michael, G., 2013. Planetary surface dating from crater size/frequency distribution measurements: multiple resurfacing episodes and differential isochron fitting. Icarus 226, 885-890.

Michael, G.G., Kneissl, T., Neesemann, A., 2016. Planetary surface dating from crater sizefrequency distribution measurements: poisson timing analysis. Icarus 277, 279-285.

Neveu, M., Desch, S.J., Castillo-Rogez, J.C., 2017. Aqueous geochemistry in icy world interiors: equilibrium fluid, rock, and gas compositions, and fate of antifreezes and radionuclides. Geochimica et Cosmochimica Acta 212, 324-371.

Palomba, E., Longobardo, A., Sanctis, M.C., Stein, N., Ehlmann, B., Galiano, A., Raponi, A., Ciarniello, M., Ammannito, E., Cloutis, E., Carrozzo, F.G., Capria, M.T., Stephan, K., Zambon, F., Tosi, F., Raymond, C.A., Russell, C.T., 2017. Compositional differences among Bright Spots on the Ceres surface. Icarus, In Press.
Park, R.S., Konopliv, A.S., Bills, B.G., Rambaux, N., Castillo-Rogez, J.C., Raymond, C.A., Vaughan, A.T., Ermakov, A.I., Zuber, M.T., Fu, R.R., Toplis, M.J., Russell, C.T., Nathues, A., Preusker, F., 2016. A partially differentiated interior for (1) Ceres deduced from its gravity field and shape. Nature 537, 515-517.

Perkel, J., 2016. Democratic databases: science on GitHub. Nature News 538, 127.

Prettyman, T.H., Feldman, W.C., McSween, H.Y., Dingler, R.D., Enemark, D.C., Patrick, D.E., Storms, S.A., Hendricks, J.S., Morgenthaler, J.P., Pitman, K.M., Reedy, R.C., 2011. Dawnś gamma ray and Neutron detector. Space Sci. Rev. 163, 371-459.

Preusker, F., Scholten, F., Matz, K.-D., Elgner, S., Jaumann, R., Roatsch, T., Joy, S.P., Polanskey, C.A., Raymond, C.A., Russell, C.T., 2016. Dawn at Ceres shape model and rotational state. In: 46th LPSC, pp. 1954.

Roatsch, T., Kersten, E., Matz, K.-D., Preusker, F., Scholten, F., Jaumann, R., Raymond, C.A., Russell, C.T., 2016. High-resolution Ceres high altitude mapping orbit atlas derived from dawn framing camera images. Planet. Space Sci. 129, 103-107.

Roatsch, T., Kersten, E., Matz, K.-D., Preusker, F., Scholten, F., Jaumann, R., Raymond, C.A., Russell, C.T., 2017. High-resolution Ceres low altitude mapping orbit Atlas derived from Dawn framing camera images. Planet. Space Sci. 140, 74-79.

Russell, C.T., Raymond, C.A., 2011. The dawn mission to Vesta and Ceres. Space Sci. Rev. 163, 3-23.

Schenk, P., Sizemore, H., Schmidt, B., Castillo-Rogez, J., De Sanctis, M.C., Bowling, T., Scully, J., Buczkowski, D., Quick, L., Preusker, F., Park, R., Raymond, C.A., Russell, C.T., the Dawn Science Team, 2018. The Central Pit and Dome at Cerealia Facula Bright Deposit and Floor Deposits in Occator Crater, Ceres. Icarus In Press.

Schröder, S.E., Mottola, S., Carsenty, U., Ciarniello, M., Jaumann, R., Li, J.-Y. Longobardo, A., Palmer, E., Pieters, C., Preusker, F., Raymond, C.A., Russell, C.T., 2017. Resolved spectrophotometric properties of the Ceres surface from Dawn Framing Camera images. Icarus 288, 201-225.

Scully, J.E., Buczkowski, D., Schmedemann, N., Raymond, C.A., Castillo-Rogez, J.C., King, S., Bland, M., Ermakov, A., O'Brien, D., Marchi, S., 2017. Evidence for the Interior Evolution of Ceres from Geologic Analysis of Fractures. Geophysical Research Letters 44, 9564-9572.

Scully, J.E.C., Buczkowski, D.L., Neesemann, A., Williams, D.A., Mest, S.C., Raymond, C.A., Nass, A., Hughson, K.H.G., Kneissl, T., Pasckert, J.H., Ruesch, O., Frigeri, A., Marchi, S., Combe, J.-P., Schmedemann, N., Schmidt, B.E., Chilton, H.T., Russell, C.T., Jaumann, R., Preusker, F., Roatsch, T., Hoffmann, M., Nathues, A., Schaefer, M., Ermakov, A.I., 2018Scully et al.,. Ceres' Ezinu quadrangle: a heavily cratered region with evidence for localized subsurface water ice and the context of Occator crater. Icarus 316, 46-62.

Sierks, H., Keller, H.U., Jaumann, R., Michalik, H., Behnke, T., Bubenhagen, F., Büttner, I., Carsenty, U., Christensen, U., Enge, R., Fiethe, B., Gutiérrez Marqués, P., Hartwig, H., Krüger, H., Kühne, W., Maue, T., Mottola, S., Nathues, A., Reiche, K.-U., Richards, M.L., Roatsch, T., Schröder, S.E., Szemerey, I., Tschentscher, M., 2011. The Dawn Framing Camera. Space Sci. Rev. 163, 263-327.

Stephan, K., Jaumann, R., Krohn, K., Schmedemann, N., Zambon, F., Tosi, F., Carrozzo, F., McFadden, L., Otto, K., De Sanctis, M., et al., 2017. An investigation of the bluish material on Ceres. Geophys. Res. Lett. 44, 1660-1668.

Steininger, S., Bocher, E., 2009. An overview on free and open source GIS developments. Int. J. Geog. Inf. Sci. 23, 1345-1370.

Stein, N., Ehlmann, B., Palomba, E., De Sanctis, M.C., Nathues, A., Hiesinger, H., Ammannito, E., Raymond, C., Jaumann, R., Longobardo, A, Russell, C.T., 2017. The formation and evolution of bright spots on Ceres. Icarus, In Press.

Thangjam, G., Nathues, A., Platz, T., Hoffmann, M., Cloutis, E., Mengel, K., Izawa, M., Applin, D, 2018. Spectral properties and geology of bright and dark material on dwarf planet Ceres. Meteorit. Planet. Sci. In Press, https://doi.org/10.1111/maps.13044.

Williams, D.A., Yingst, R.A., Garry, W.B., 2014. Introduction: The geologic mapping of Vesta. Icarus 244, 1-12.

Williams, D.A., Kneissl, T., Neesemann, A., Mest, S.C., Palomba, E., Platz, T., Nathues, A., Longobardo, A., Scully, J., Ermakov, A., Jaumann, R., Buczkowski, D.L., Schafer, M., Thangjam, G., Pieters, C.M., Roatsch, T., Preusker, F., Marchi, S., Schmedemann, N., Hiesinger, H., Frigeri, A., Raymond, C.A., Russell, C.T., 2018a. The geology of the Kerwan quadrangle of dwarf planet Ceres: investigating Ceres' oldest, Largest Impact Basin. Icarus 316, 99-113.

Williams, D.A., Buczkowski, D.L., Mest, S.C., Scully, J.E.C., Platz, T., Kneissl, T., 2018b. Introduction: The geologic mapping of Ceres. Icarus 316, 1-13.

Yingst, R.A., Mest, S.C., Berman, D.C., Garry, W.B., Williams, D.A., Buczkowski, D., Jaumann, R., Pieters, C.M., De Sanctis, M.C., Frigeri, A., Le Corre, L., Preusker, F., Raymond, C.A., Reddy, V., Russell, C.T., Roatsch, T., Schenk, P.M., 2014. Geologic mapping of Vesta. Planet. Space Sci. 103, 2-23. 